\title{
Management of Pseudophakic Retinal Detachments by Endovitreal Surgery with Vitreal Cavity Tamponade by Silicone Oil and Air-Gas Mixture
}

DOI: 10.17691/stm2016.8.1.21

Received October 13, 2015

A.D. Chuprov, MD, DSc, Head Physician ${ }^{1 ;}$ Head of Ophthalmology Department²;

L.V. Demakova, Ophthalmologist ${ }^{1}$; Assistant of Ophthalmology Department ${ }^{2}$

${ }^{1}$ Kirov Clinical Ophthalmological Hospital, 10a Oktyabrsky Avenue, Kirov, 610011, Russian Federation; ${ }^{2}$ Kirov State Medical Academy, 32, Bldg. 2 Proletarskaya St., Kirov, 610000, Russian Federation

The aim of the investigation was to assess the efficacy of using air-gas mixture as a substitute for vitreous body in microinvasive surgical management of primary pseudophakic retinal detachment (PRD) and its recurrence after extrascleral intervention performed by $25 \mathrm{G}$ endovitreal surgery technique.

Materials and Methods. Two groups of patients, which underwent vitrectomy with tamponade of the vitreal cavity by silicone oil or gas, were formed: group $1(n=24)$ with primary unoperated PRD and group $2(n=10)$ with recurrent PDR after extrascleral surgery. Both groups were further divided into subgroups: A — patients with vitrectomy and introduction of silicone oil; B — patients with vitrectomy and air-gas mixture.

Results. A comparative analysis of PRD surgical treatment data, carried out in our investigation, showed that in case of primary PRD treatment higher anatomical and functional results were achieved, when vitrectomy was made with application of silicone oil, which performed more controlled and prolonged tamponade of the vitreal cavity than in vitrectomy with replacement of the vitreous body by air-gas mixture.

In case of PRD recurrence after extrascleral surgery greater efficacy in comparison with the application of the silicone oil was revealed in vitrectomy and air-gas tamponade of the vitreal cavity if there were no coarse retinal fibrosis and large extension of redetached retina.

Conclusion. Only differentiated approach to the choice of temporal substitute of vitreous body after vitrectomy in patients with pseudophakic retinal detachment will allow the surgeons to achieve maximally feasible anatomical and functional results.

Key words: pseudophakic retinal detachment; endovitreal surgery; vitrectomy; silicone oil; air-gas mixture.

Retinal detachment occupies about $9 \%$ among the causes of vision disability, $84 \%$ being people of active working age [1]. A special group among patients with retinal detachment comprises people which have been operated previously for cataract with intraocular lens implantation. Changes inside the eye due to cataract surgery predispose to the development of proliferative vitreoretinopathy (PVR) and, as a consequence, to traction and combined rhegmatogenous and traction retinal detachment [2].

The choice of the method and extent of surgical intervention determine in many respects the results of the treatment. Multiple or superior tears and breaks, elderly age, old retinal detachments, PVR stage $C$ and $D$ are considered indications to endovitreal surgery (EVS). As patients with pseudophakic retinal detachment (PRD) have a high risk of PVR development and its more prominent and rapid course compared to phakic detachments, surgeons prefer to perform primarily endovitreal intervention. The tactics of patient management with this pathology is variable, individual in each case, and subjective. The aim of retinal detachment surgical treatment is smoothing out and complete adaptation of the retina in the postoperative period [3]. At present a gold standard of endovitreal approach in case of heavy retinal detachment, including PRD, is transscleral microinvasive vitrectomy with the following tamponade of the vitreal cavity by silicon oil [3-5]. Despite a high efficacy of this method, recurrences occur in $21.4-77 \%$ of cases, according to the data of various authors [6-10]. They may be caused by PVR progression, incomplete removal of the vitreous body during primary vitrectomy, formation of new and unblocking of old ruptures, secondary surgical interventions [11-13].

Performing EVS of retinal detachment a whole number of factors should be taken into consideration: extent, vitrectomy technique, revisions of the vitreal cavity; the need and ways of performing retinotomy and/ or retinectomy, elimination of subretinal liquid; choice of vitreous body substitutes (silicone oil, gas) and terms of leaving silicone oil in the eye $[13,14-16]$.

The silicone oil fills in retinal defects of any size and localization in the adjacent retina free of a tractional component, as well as the vitreal cavity space, preventing free movement of proliferative cells and chemical mediators of inflammation and limiting the spread of proliferative process; it also decreases reduction of epiretinal membranes and directs the vector of the traction forces along the retinal surface (resulting

For contacts: Lyubov V. Demakova, e-mail: oftalmologiikgma@mail.ru 
in a flatter and area-limited character of the recurrent detachment); partially packs retinal vessels and prohibits blood and fibrin from propagation across the vitreal cavity (reduces the risk of secondary bleeding and proliferation); provides transparency of optical media, enabling retina examination in the postoperative period and, if necessary, performance of supplementary laser coagulation; stabilizes intraocular pressure in case of hypotension, preventing subatrophy, at least for some period [3]. However, complications are possible in vitrectomy with silicone tamponade, caused directly by the presence of silicone oil in the vitreal cavity: penetration of silicone oil into subretinal, suprachorioidal and subarachnoidal spaces, secondary glaucoma, emulsification, keratopathy, reproliferation [17].

Gas tamponade is an alternative to silicone oil in making vitrectomy [18]. The obligatory condition of successful treatment in this technology is a strict observation of a face-down position of the patient in the postoperative period. Nowadays such gases as $\mathrm{SF}_{6}, \mathrm{C}_{2} \mathrm{~F}_{6}$, $\mathrm{C}_{3} \mathrm{~F}_{8}$ are used for vitreal cavity tamponade. Indications to gas tamponade are: extension of detached retina from 1 to 2 quadrants, absence of fibrosis and retinal edema in the zone of retinal defect, i.e. PVR, stages $A$ and $B$, and cases of total removal of local subretnal fibrosis and dissection of epiretinal membranes after mobilization of the retina is achieved [19].

The aim of the investigation was to assess the efficacy of using air-gas mixture as a substitute for vitreous body in microinvasive surgical management of primary pseudophakic retinal detachment and its recurrence after extrascleral intervention performed by 25G endovitreal surgery technique.

Materials and Methods. The results of 25G EVS with silicone oil and gas tamponade of the vitreal cavity in 34 patients, suffering from retinal detachment in pseudoaphakic eyes, have been retrospectively analyzed. An average age of the patients was 62 years (47-81 years). Standard ophthalmologic examination was carried out to all patients before operative treatment.

Two groups of patients, which underwent vitrectomy with vitreal cavity tamponade by silicone oil or air-gas mixture, were formed: group $1 \quad(n=24)$ with primary unoperated PRD and group $2(n=10)$ with recurrent PRD after extrascleral surgery. Both groups were further divided into subgroups: A - patients with vitrectomy and injection of silicone oil; B - patients with vitrectomy and air-gas mixture.

All operations were performed using Millenium (Baush\&Lomb, USA) microsurgical system. The technique of primary posterior closed subtotal vitrectomy was standard: through 3 punctures using 25G technology in the area of the planar part of the ciliary body. The operation was accomplished by endotamponade of the vitreal cavity with 1,300 cSt of silicone oil or air-gas mixture in standard concentrations (fluorinated gas $\mathrm{SF}_{6}$, sulphur hexafluoride, or $\mathrm{C}_{2} \mathrm{~F}_{6}$, (Arceole) hexafluoroethane).

During vitreal cavity revision epiretinal membranes were removed with a straight retinal forceps in water medium. Retinotomy was performed by a vitreotom within the limits of fibrously changed retina in the medium of perfluoroorganic compounds. Once a complete adaptation of the retina was achieved, these compounds were removed in the air and tamponade of the vitreal cavity was performed using air-gas mixture or 1,300 cSt silicone oil. Endolasercoagulation was conducted around the break and along the retinotomy margin.

Analyzing the results of PRD surgery, indications for vitreal cavity tamponade by silicone oil or air-gas mixture, anatomical adhesion of the retina, presence and terms of the recurrent detachment, visual acuity prior to and 1 month after surgery, outcomes of PRD treatment have been evaluated.

Results and Discussion. In group 1 PRD duration by the time of patients' visits to the ophthalmologist ranged from 1 day to 6 months in subgroup $A(n=17)$ and from 1 to 16 days in subgroup $B(n=7)$. PRD was total and subtotal with PVR stages II-IV in the subgroup $A$ and stages $\|-\| I \|$ in the subgroup $B$. Thus, long duration of PRD and the extent of PVR intensity were indications for primary vitrectomy with vitreal cavity tamponade by silicone oil. There were no complications in the course of the operation. In the postoperative period complications were observed in $64.7 \%$ (in 11 of 17 ) in subgroup $1 \mathrm{~A}$ and in $71.4 \%$ (in 5 of 7 ) in subgroup 1B (Table 1).

Patients with primary PRD, who underwent vitrectomy with vitreal cavity tamponade by silicone oil (Table 2), had higher functional and anatomical results.

Table 1

Complications in the postoperative period after primary vitrectomy with a tamponade of the vitreal cavity by various vitreous body substitutes (abs. number/\%)

\begin{tabular}{lccccccc}
\hline \multicolumn{1}{c}{ Groups } & $\begin{array}{c}\text { Secondary } \\
\text { glaucoma }\end{array}$ & Hypertension & $\begin{array}{c}\text { Opacity } \\
\text { of silicone }\end{array}$ & $\begin{array}{c}\text { Epivitreal } \\
\text { membranes }\end{array}$ & Keratopathy & Torpid uveitis & $\begin{array}{c}\text { Penetration } \\
\text { of silicone into } \\
\text { anterior chamber }\end{array}$ \\
\hline $\begin{array}{l}\text { Silicone oil } \\
\text { (subgroup 1A) }\end{array}$ & $3 / 17.6$ & $4 / 23.5$ & $1 / 5.9$ & $2 / 11.8$ & $2 / 11.8$ & $2 / 11.8$ & $1 / 5.9$ \\
\hline $\begin{array}{l}\text { Air-gas mixture } \\
\text { (subgroup 1B) }\end{array}$ & $1 / 14.3$ & $2 / 28.6$ & - & $3 / 42.9$ & - & $2 / 28.6$ & - \\
\hline
\end{tabular}


Table 2

Results of surgical treatment of primary pseudophakic retinal detachment using vitrectomy with a vitreal cavity tamponade by silicone oil and air-gas mixture

\begin{tabular}{|c|c|c|c|c|c|}
\hline Groups & $\begin{array}{l}\text { Vision acuity before surgery } \\
\text { of pseudophakic retinal } \\
\text { detachment }\end{array}$ & $\begin{array}{l}\text { Visual acuity } 1 \text { month } \\
\text { after the operation }\end{array}$ & $\begin{array}{c}\text { Increase } \\
\text { of visual acuity }\end{array}$ & $\begin{array}{l}\text { Retinal } \\
\text { adhesion }\end{array}$ & Occurrences \\
\hline $\begin{array}{l}\text { Silicone oil } \\
\text { (subgroup 1A) }\end{array}$ & $\begin{array}{l}0.05 \text { (average) (p.l. certa }-0.2) \\
<0.1-\text { in } 76.5 \%(13 \text { of } 17)\end{array}$ & $\begin{array}{l}0.2 \text { (average) (p.l. certa }-0.6) \\
\geqslant 0.1-\text { in } 70.6 \%(12 \text { of } 17)\end{array}$ & $\begin{array}{c}82.4 \% \\
(14 \text { of } 17)\end{array}$ & $\begin{array}{c}76.5 \% \\
(13 \text { of } 17)\end{array}$ & $\begin{array}{l}23.5 \% \\
(4 \text { of } 17)\end{array}$ \\
\hline $\begin{array}{l}\text { Air-gas mixture } \\
\text { (subgroup 1 B) }\end{array}$ & $\begin{array}{c}0.02 \text { (average) (p.l. certa }-0.1) \\
<0.1-\text { in } 85.7 \%(6 \text { of } 7)\end{array}$ & $\begin{array}{c}0.2 \text { (average) (p.l. certa }-0.8) \\
\quad \geqslant 0.1-42.9 \%(3 \text { of } 7)\end{array}$ & $\begin{array}{l}71.4 \% \\
(5 \text { of } 7)\end{array}$ & $\begin{array}{l}85.7 \% \\
(6 \text { of } 7)\end{array}$ & $\begin{array}{l}85.7 \% \\
(6 \text { of } 7)\end{array}$ \\
\hline
\end{tabular}

Table 3

Results of surgical treatment of recurrent pseudophakic retinal detachment after extrascleral surgery using vitrectomy with a vitreal cavity tamponade by silicone oil and air-gas mixture

\begin{tabular}{|c|c|c|c|c|c|}
\hline Groups & $\begin{array}{c}\text { Vision acuity before surgery } \\
\text { of pseudophakic retinal } \\
\text { detachment }\end{array}$ & $\begin{array}{l}\text { Visual acuity } 1 \text { month } \\
\text { after the operation }\end{array}$ & $\begin{array}{c}\text { Increase } \\
\text { of visual acuity }\end{array}$ & $\begin{array}{l}\text { Retinal } \\
\text { adhesion }\end{array}$ & Occurrences \\
\hline $\begin{array}{l}\text { Silicone oil } \\
\text { (subgroup 2A) }\end{array}$ & $\begin{array}{c}0.008 \text { (average) }(0.005-0.1) \\
<0.1-\text { in } 100 \%\end{array}$ & $\begin{array}{l}0.08 \text { (average) }(0.005-0.2) \\
\geqslant 0.1-\text { in } 60 \%(3 \text { of } 5)\end{array}$ & $\begin{array}{c}60 \% \\
(3 \text { of } 5)\end{array}$ & $\begin{array}{c}40 \% \\
(2 \text { of } 5)\end{array}$ & $\begin{array}{c}20 \% \\
(1 \text { of } 5)\end{array}$ \\
\hline $\begin{array}{l}\text { Air-gas mixture } \\
\text { (subgroup 2B) }\end{array}$ & $\begin{array}{c}0.02 \text { (average) (p.l. certa - 0.08) } \\
<0.1-\text { in } 100 \%\end{array}$ & $\begin{array}{c}0.07 \text { (average) (p.l. certa }-0.2) \\
\geqslant 0.1-\text { in } 60 \%(3 \text { of } 5)\end{array}$ & $\begin{array}{c}80 \% \\
(4 \text { of } 5)\end{array}$ & $\begin{array}{c}100 \% \\
(5 \text { of } 35)\end{array}$ & - \\
\hline
\end{tabular}

A large percentage of recurrences in patients, who were performed vitrectomy with gas introduction, is likely to speak of PVR progression in the zone of the retinal defect, and of the insufficient time of gas effect, as the time of tamponade action for $20 \% \mathrm{SF}_{6}$ is, for example, $10-15$ days. Gas resorption is also accelerated by torpid inflammatory processes in the eye, and impairment of hematoretinal barrier. Besides, if a face-down position of the patient in the postoperative period is disregarded, it may also result in recurrences.

In patients of both groups with recurrent PRD proliferation and/or retinal fibrosis were diagnosed on examination. In all cases revision of the vitreal cavity with removal of epiretinal membranes or performance of retinotomy, endolaser retina coagulation and injection of 1,300 cSt silicone oil were carried out during repeated surgery. In both subgroups complete adhesion of the retina was achieved after repeated surgery in case of recurrence.

In group 2 vitrectomy with vitreal cavity tamponade by silicone oil (subgroup A, 5 eyes) or by air-gas mixture (subgroup B, 5 eyes) was conducted to the patients with recurrent $P R D$ after extrascleral surgery.

Indications for endovitreal operation in subgroup $2 \mathrm{~A}$ were incomplete adhesion of the retina after extraocular surgery in $40 \%$ of patients (in 2 of 5 ) and recurrent PRD within 2 weeks-6 months after the primary surgery in $60 \%$ (in 3 of 5 ) with more than 2 quadrants of the detached retina extension. All patients were diagnosed proliferation, and subretinal fibrosis.

Indications for endovitreal operation in subgroup 2B were incomplete adhesion of the retina after extraocular surgery in $80 \%$ of patients (in 4 of 5 ) and recurrent PRD
3 years after primary surgery in 20\% (in 1 of 5 ) with the extension of the detached retina from 1 to 2 quadrants. No coarse subretinal fibrosis was revealed.

Revision of the vitreal cavity with removal of epiretinal membranes and/or with performance of retinotomy, endolaser retina coagulation and injection of 1,300 cST silicone oil or air-gas mixture were carried out during repeated surgery. There were no complications during the operation.

In group 2 higher functional and anatomical results were obtained in patients of subgroup 2B, which underwent vitrectomy with vitreal cavity tamponade by air-gas mixture (Table 3). It was connected with a small extension of redetached retina and absence of a coarse subretinal fibrosis in this subgroup relative to subgroup $2 \mathrm{~A}$, where marked proliferation and subretinal fibrosis were observed, and during vitreal cavity revision the retina failed to be fully smoothed out.

A low percent of anatomical success after vitrectomy with vitreal cavity tamponade by silicone oil in recurrent PRD after extrascleral sealing may be associated with reproliferation in the postoperative period and also with inadequate removal of the traction component from the adjacent retina in the process of vitrectomy. Gas tamponade in comparison with silicone oil tamponade has a more prominent effect owing to greater buoyancy force of the gas bubble and is effective only in complete removal of local fibrosis.

PRD is referred to "heavy" detachments, which are characterized by intensive PVR, retina fixation to the changed vitreous body, preventing its adhesion. Effective tamponade of the vitreal cavity in order to form a strong chorioretinal adhesion and to close 
retinal defects is a major object of endovitreal surgery in patients with PRD. Formation of a strong chorioretinal adhesion requires several stages: alteration, exudation, proliferation, lasting from 3 weeks to 2-3 months, depending on eye condition.

Vitrectomy with vitreal cavity tamponade by silicone oil is at present a gold standard of endovitreal approach in case of "heavy" PRD, as silicone oil performs a controlled and long-term tamponade of the vitreal cavity $[4,5]$. This is also confirmed by our investigations (See Table 2). However, some authors believe [20], that vitreal operation of any complication should be finished in a single stage by air-gas mixture, which has some advantages over silicone oil. There is no need of subsequent removing of the gas from the vitreal cavity, and, therefore repeated surgical trauma of the eye; the risk of gas penetration to the subretinal area through the retinal tears is also minimal owing to a definite value of surface tension; a more pronounced tamponade effect is produced due to a greater buoyancy force of the gas bubble - it is 16-17 times greater than that of silicone oil [3]. Certainly, in case of marked PVR and retinal edema in the zone of its tear chorioretinal adhesions by the time of gas resorption, $\mathrm{SF}_{6}$ especially, may not be adequate enough, which results in recurrent PRD. Therefore, definition of the effective time for gas tamponade is of great importance. Perfluorpropan $\left(\mathrm{C}_{3} \mathrm{~F}_{8}\right)$ is the gas, which is recommended in PVR with the effective time of tamponade of 30 days with a full resorption by day 60 .

A comparative analysis of PRD surgical treatment data, carried out in our investigation, showed that in case of primary PRD treatment higher anatomical and functional results were achieved, when vitrectomy was made with application of silicone oil, which performed more controlled and prolonged tamponade of the vitreal cavity than in vitrectomy with replacement of the vitreous body by air-gas mixture.

In case of PRD recurrence after extrascleral surgery greater efficacy in comparison with the application of silicone oil was revealed in vitrectomy and air-gas tamponade of the vitreal cavity if there were no coarse retinal fibrosis and large extension of redetached retina.

Conclusion. Only differentiated approach to the choice of temporal replacement of vitreous body after vitrectomy in patients with pseudophakic retinal detachment will allow surgeons to achieve maximally feasible anatomical and functional results.

The choice of surgery and its algorithm in primary PRD and their recurrence is variable. The extent and method of vitreal cavity tamponade during the operation is determined depending on the particular clinical situation.

Study Funding and Conflicts of Interest. The work was not supported by any sources. The author declares no conflicts of interest.

\section{References}

1. Neroev V.V., Zakharova G.Yu., Razik S. Skleroplasticheskie operatsii pri otsloyke setchatki bez razryvov.
V kn.: Sovremennye vozmozhnosti $v$ diagnostike $i$ lechenii vitreoretinal'noy patologii [Scleroplastic operations in retina detachment without tears. In: State-of-the-art resources in diagnosis and treatment of vitreoretinal pathology]. Moscow; 2004; p. 219-220.

2. Bobr T.V., Rozhko Yu.l., Sklimenok E.M. Iskhod khirurgicheskogo lecheniya otsloek setchatki na afakichnykh i artifakichnykh glazakh. V kn.: Sovremennye tekhnologii lecheniya vitreoretinal'noy patologii - 2009 [Outcome of surgical retinal detachment treatment on aphakic and pseudoaphakic eyes. In: Up-to-date technologies of treating vitreoretinal pathology - 2009]. Moscow; 2009. URL: http://www.eyepress. ru/article.aspx?6655.

3. Zakharov V.D., Khodzhaev N.S., Gorshkov I.M., Malyatsinskiy I.A. Current surgery of retinal detachment recurrence. Review. Oftal'mologiya 2012; 9(1): 10-13.

4. Riemann C.D., Miller D.M., Foster R.E., Petersen M.R. Outcomes of transconjuctival suture - less 25 gauge vitrectomy with silicone oil infusion. Retina 2007; 27(3): 296-303, http:// dx.doi.org/10.1097/01.iae.0000242761.74813.20.

5. Shah C.P., Ho A.C., Regillo C.D., Fineman M.S., Vander J.F., Brown G.C. Short-term outcomes of 25-gauge vitrectomy with silicone oil for repair of complicated retinal detachment. Retina 2008; 28(5): 723-728, http://dx.doi. org/10.1097/IAE.0b013e318166976d.

6. Takhchidi Kh.P., Kazaikin V.N., Rapoport A.A. Tamponade of the vitreal cavity with silicone oil in the surgery of retinal detachment. Relapses of retinal detachment. Oftal'mologiya 2004; 2: 29-33.

7. Takhchidi Kh.P., Kazaykin V.N., Rapoport A.A. Surgical treatment of retinal detachment recurrence, originated during vitreal cavity tamponade by silicone oil. Oftal'mokhirurgiya 2005; 3: 20-24.

8. Kapran Z., Uyar O.M., Kaya V., Eltutar K. Reccurences of retinal detachement after vitreoretinal surgery, surgical approach. Eur J Ophthalmol 2001; 11(2): 166-170.

9. La Heij E.C., Kessels A.G., Hendrikse F. Results and complications of temporary silicone oil tamponade in patients with complicated retinal detachments. Retina 2001; 21(2): 107-114, http://dx.doi.org/10.1097/ 00006982-200104000-00002.

10. Lam R.F., Cheung B.T., Yuen C.Y., Wong D., Lam D.S., Lai W.W. Retinal redetachment after silicone oil removal in proliferative vitreoretinopathy: a prognostic factor analysis. Am J Ophthalmol 2008; 145(3): 527-533, http://dx.doi.org/10.1016/ j.ajo.2007.10.015.

11. Zakharov V.D., Balinskaya N.R., Lazarenko L.F. Combined intravitral surgical interventions in retinal detachment, complicated by vitreoretinal traction. Oftal'mokhirurgiya 1997; 1 : 28-34.

12. Takhchidi Kh.P., Kazaykin V.N. Silicon tamponade in modern surgery of retinal detachment. Vestnik oftal'mologii 2004; 2 : 41-45.

13. Goezinne F., La Heij E.C., Berendschot T.T., Liem A.T., Hendrikse F. Risk factors for redetachment and worse visual outcome after silicone oil removal in eyes with complicated retinal detachment. Eur J Ophthalmol 2007; 17(4): 627-637.

14. Zakharov V.D., Khusseyn M.I. Vitreoretinal surgery in retinal detachment, complicated by anterior proliferative vitreoretinopathy. Oftal'mokhirurgiya 2007; 1: 38-41.

15. Rapoport A.A., Kazaykin V.N. Intravitreal gas injection after ineffective scleral buckling for retinal detachment. Oftal'mokhirurgiya 2012; 2: 18-21. 
16. Li H., Zhu X., Jiang D. Risk factors of retinal detachment after expected silicone oil removal. Yan Ke Xue Bao 2005; 21(2): 92-98.

17. Chen J.X., Nidecker A.E., Aygun N., Gujar S.K., Gandhi D. Intravitreal silicone oil migration into the subarachnoid space and ventricles: a case report and review of literature. European Journal of Radiology Extra 2011; 78(2): e81-e83, http://dx.doi. org/10.1016/j.ejrex.2011.02.004.

18. Hwang J.-F., Chen S.-N., Lin C.-J. Treatment of inferior rhegmatogenous retinal detachment by pneumatic retinopexy technique. Retina 2011; 31(2): 257-261, http://dx.doi. org/10.1097/iae.0b013e3181e586f9.
19. Malyatsinskiy I.A., Zakharov V.D., Khodzhaev N.S., Gorshkov I.M. Results of surgical treatment for an inferior localized retinal detachment recurrence by partial retinotomy using $25 \mathrm{G}$ microinvasive endovitreal surgery. Prakticheskaya meditsina. Oftal'mologiya 2012; 4(12 Suppl 2). URL: http://pmarchive.ru/ rezultaty-xirurgicheskogo-lecheniya-recidiva-otslojki-setchatki-vnizhnem-segmente-s-provedeniem-chastichnoj-retinotomii-naosnove-mikroinvazivnoj-endovitrealnoj-xirurgii-25-g/.

20. Bartz-Schmidt U., Szurman P., Wong D., Kirchhof B. New developments in retinal detachment surgery. Der Ophthalmologe 2008; 105(1): 27-36, http://dx.doi.org/10.1007/s00347-0071662-2. 